\title{
Axiomatic Design based Design of a Software Prototype for Smart Shopfloor Management
}

\author{
Erwin Rauch ${ }^{1,}$, Andrew Vickery $^{2}$, Manuel Garcia ${ }^{1}$, Rafael Rojas ${ }^{1}$ and Dominik T. Matt ${ }^{1,3}$ \\ ${ }^{1}$ Faculty of Science and Technology, Free University of Bozen-Bolzano, Bolzano, 39100 Italy \\ ${ }^{2}$ Dept. of Mechanical Engineering, Worcester Polytechnic Institute, Worcester, 01609, MA, USA \\ ${ }^{3}$ Innovation Engineering Center, Fraunhofer Italia Research scarl, Bolzano, 39100, Italy
}

\begin{abstract}
Shopfloor management systems are currently undergoing a change. With the era of Industry 4.0, traditional shop floor management concepts are changing to new and digitally supported approaches for the coordination and management of production at the shop floor level. In order to investigate this change, the research project "Smart Shopfloor" is aiming to develop a software prototype for production management in the era of Industry 4.0. Requirements of industry are collected through literature review and workshops with industry and are translated into software functionalities. These functionalities lead, via an Axiomatic Design (AD) decomposition to design solutions for Smart Shop Floor Management systems. The results of the AD study form the basis for the software architecture and the definition of core and add-on functionalities of the software prototype. The focus of this paper lies on the $\mathrm{AD}$ decomposition of the design concept and further gives an overview of potential functionalities. In future, the developed concept will then be implemented in a lab environment before implementing and testing it in industrial case studies.
\end{abstract}

\section{Introduction}

In recent years, the industrial environment is changing radically with the introduction of industry 4.0. In order to use and to implement new and emerging technologies for digitization and connectivity efficiently, fundamental changes and adaptations in the production of products are necessary [1]. Through the introduction of so called cyber-physical systems (CPS) and the internet of things (IoT) data models work in real time and the production becomes transparent [2]. Production data are provided in a completely new quality supporting production to manufacture individual products [3] and to make complex decisions faster and thus to be more reactive [2].

Shopfloor management (SFM) is a widely used instrument for operative production control and management in manufacturing companies, which primarily includes detecting deviations and problems in the operational environment and systematically solving these problems $[4,5]$. Over the past decades, SFM has been strongly influenced by methods and tools from lean production and quality management $[6,7]$. The era of industry 4.0 and the trend towards digitization in production will significantly change the current image of SFM.

In this work, the development of SFM is analysed over time based on a literature review. Afterwards a modern approach of smart shop floor management (SSFM) and related software applications will be presented and explained. These are further underpinned and explained by a practical example.

\section{Theoretical background - Smart Shopfloor Management in the industry 4.0 era}

The theory section presents a brief overview and the state of the art regarding Shopfloor Management in the past and how it will change with the introduction of Industry 4.0.

In the future, production data will be provided in a completely new quality and with real-time information about production processes. This is made possible by the comprehensive equipping of production with sensors for data acquisition and the consistent integration of intelligent objects $[2,3]$. The future representation of the data models in real time makes production transparent and thus easier to control. In the future, such a production control system can also cope with short-term changes in demand and capacity utilization and make complex decisions decentralized in a human-centred production environment [2]. The digitisation and collection of production data promises better use of the data in the use of shopfloor management to increase efficiency and sustainability [4].

Due to increasingly adaptable production systems and the introduction of Industry 4.0 in companies, the pursuit of economies of scale as a means of reducing costs is losing importance, as many process steps can be combined much more flexibly. This means that customerspecific production at low costs is possible with connected production technologies. In classic production systems,

\footnotetext{
* Corresponding author: erwin.rauch@unibz.it
} 
this is only possible through frequent variant changes or execution of individual production steps, which usually means higher costs [8].

A critical success factor in global competition is and remains the ability to make the right decisions in a short time. The comprehensive real-time transparency in industry 4.0 enables early decision making and flexible reactions to turbulence in production as well as global optimization across locations. The overall goals, such as the highest possible output (resource productivity) and the lowest possible use of resources for a given product quantity (resource efficiency), are also maintained in industry 4.0. Production processes can be optimized by CPS and throughout the entire value chain [9]. In addition, it is becoming increasingly important to continuously monitor and optimize the system during production with regard to resource and energy consumption as well as emissions $[10,11]$.

The "smart factory" can control complex and geographically distributed industrial processes. It describes a production environment consisting of intelligent, self-controlling objects. Self-controlled objects can be containers, products, devices or materials. Smart Products are an example of such self-directed objects and can be clearly identified and localized at any time. They already have the knowledge of their manufacturing process. Smart products will therefore be able to independently control the various stages of their production in the future [10].

The introduction of CPS in production also leads to a change in working conditions for employees in the production environment. Employees benefit from more flexible, age-appropriate and, through the use of assistance systems, simpler workstations with greater responsibility and independence in work design. In addition to positive influencing factors, however, employees also face a higher work density and higher demands on competences and skills in dealing with CPS [12].

\section{Current functionalities of the Smart Shopfloor Management software Visual Shopfloor ${ }^{\circledR}$}

In traditional lean management, SFM has often taken place in the so-called lean war room (Japanese obeya) with the support of analogue visualization and communication tools. The digitization of SFM requires the introduction of SSFM systems and applications. As described in [5], such mobile and web based software applications are a suitable instruments for connecting employees, methods and technologies in SFM.

Based on existing expertise in industrial companies the research partner Solunio $\mathrm{GmbH}$ developed a commercial software for smart shopfloor management with three layers (see Figure 1).

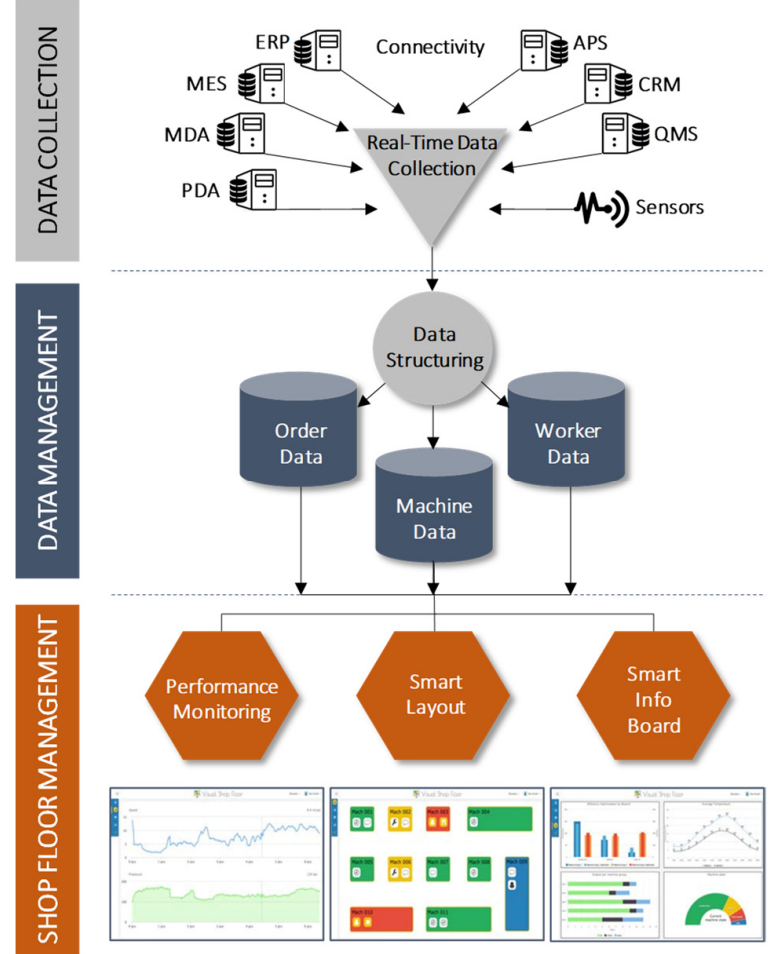

Fig. 1. Existing functionalities of the commercial software Visual Shopfloor ${ }^{\circledR}$ from Solunio GmbH.

\subsection{Data collection}

At layer 1 (Data Collection), data are collected by connecting the SSFM application with various systems and equipment in the company. Such systems can be the internal ERP (enterprise resource planning), a MES (manufacturing execution system) or MDA/PDA (machine or production data acquisition), as well as specific systems such as CRM (customer relationship management), APS (advanced planning system), QMS (quality management system) or intelligent sensors installed on machines.

\subsection{Data structuring and management}

At layer 2 (Data Management), all data collected is then aggregated and structured by filtering relevant data and transferring it into structured data models. The initially large data flood ('big data') is thus transformed into smart and relevant data ('smart data'). The data are then grouped into (i) order data, (ii) machine data and (iii) worker data.

\subsection{Current shopfloor management functions}

Layer 3 (Shopfloor Management) uses the data for shopfloor management by means of various functions. The "Performance Monitoring" function makes it possible to display Key Performance Indicators (KPIs) or statistics in real time avoiding complex updating of reports. The "Smart Info Board" function enables general information to be displayed to all or specific monitors in production at the touch of a button, eliminating the need for time- 
consuming manual update of paper. The "Smart Layout" function enables the user to visualize the current situation in production by means of a dynamic graphical layout representation. If the user zooms in or out, more details such as machine status or job data appear.

\section{Design of a software prototype for Smart Shopfloor Management with AD}

In this section, a short overview of the use of Axiomatic Design for software design is presented. Afterwards, the research team analyses the input of potential industrial users and applies AD to deduce a design concept for a new and extended version of Visual Shopfloor in sense of a Smart Shopfloor Management software prototype.

\subsection{Design of software systems based on Axiomatic Design}

Axiomatic Design theory is applicable to many different kinds of systems, including machines, large systems, organizations as well as software systems [13]. According to [13] software development can be done efficiently in the shortest possible time, reliably with full confidence when it is done based on axiomatic design.

In Axiomatic Design [14] requirements (CNs customer needs or attributes) are translated into functional requirements (FRs) and constraints (Cs). Hereafter starts a mapping process selecting design parameters (DPs) for individually fulfilling each FR. The following four domains form the base of the Axiomatic Design methodology [14]:

- Customer domain: the customer domain defines the desires and needs of customer, usually defined as customer needs (CNs).

- Functional domain: the functional domain focuses on the functional (FRs) and non-functional requirements (n-FR) of the system, which derive from customer needs. System constraints (Cs) are also considered.

- Physical domain: the physical domain contains the design parameters (DPs) that help to satisfy the functional requirements.

- Process domain: the process domain transforms the design parameters into real process variables (PVs).

The mapping process in $\mathrm{AD}$ then enables the application of the Independence Axiom and the Information Axiom. The Independence Axiom means that Axiomatic Design favors DPs that do not influence FRs other than the one they were selected to fulfil (means a diagonal design matrix and therefore an uncoupled design). In case of a triangular design matrix the design is a decoupled design satisfying the Independence Axiom if the design sequence is correct. If the design matrix is neither diagonal nor triangular (coupled design) a redesign of the system is required. Furthermore, the Information Axiom assures that in case of alternative satisfactory DPs, the best DP has the lowest information content required for success, i.e., least complexity, or greatest probability of success. Through a top-down decomposition approach FR-DP pairs are decomposed from an abstract level to a detailed one. In the following both Axioms are described more in detail [14]:

- Axiom 1-Independence Axiom: the design of a system is considered ideal if all functional requirements are independent of the others in order to avoid any kind of interaction among them. Each defined design parameter is only related to one functional requirement and has no influence on other functional requirements.

- Axiom 2 -Information Axiom: the Information Axiom helps the designer to choose among multiple possible solutions. The design parameter should have the smallest information content, to ensure a higher probability to satisfy a requirement. The aim is to minimize the information content of the design.

In case of software design there are some small differences to other system designs. In the case of products, DPs may be physical parameters or parts or assemblies, whereas in the case of software, DPs may be software modules or program code segments. The software modules build a software architecture which provides a good guideline for software development [13]. In $\mathrm{AD}$ a 'module' is defined as the row of design matrix that yields the FR of the row when it is multiplied by the corresponding DP [15].

\subsection{Customer needs (CNs) for shopfloor management in the era of industry 4.0}

Based on the determination of customer needs and system requirements in workshops with industrial companies and a subsequent discussion with experts the following summary of CNs was elaborated (see Figure 2).

\begin{tabular}{|c|c|c|}
\hline DATA COLLECTION & DATAANALYSIS & DATAACCESS \\
\hline $\begin{array}{l}\text { - real time data } \\
\text { - machine data } \\
\text { - inventory data } \\
\text { - energy consumption } \\
\text { - staff information } \\
\text { - process information }\end{array}$ & $\begin{array}{l}\text { - data analytics algorithms } \\
\text { - event-based warning and } \\
\text { early warning systems } \\
\text { - automatic maintenance } \\
\text { detection }\end{array}$ & $\begin{array}{l}\text { - reduction of routes for } \\
\text { information procurement } \\
\text { - terminals for employees } \\
\text { - access with mobile } \\
\text { devices }\end{array}$ \\
\hline MONITORING & VISUALIZATION & CONNECTIVITY \\
\hline $\begin{array}{l}\text { - cockpit per management } \\
\text { level } \\
\text { - production status } \\
\text { - machine status } \\
\text { - performance/efficiency } \\
\text { - alarm in case of deviation }\end{array}$ & $\begin{array}{l}\text { - work instructions, quality } \\
\text { checklists, inspection } \\
\text { plans, order data, tool data } \\
\text { - paperless production }\end{array}$ & $\begin{array}{l}\text { - standardized interfaces } \\
\text { - uninternupted data flow } \\
\text { - consistency of data in } \\
\text { different systems }\end{array}$ \\
\hline EMPLOYEES & USER-FRIENDLINESS & DECISION MAKING \\
\hline $\begin{array}{l}\text { - acceptance of employees } \\
\text { - allocation of jobs } \\
\text { according to age and } \\
\text { competence } \\
\text { - new competencies in data } \\
\text { management required }\end{array}$ & $\begin{array}{l}\text { - intuitive user guidance } \\
\text { - recognition of the role of } \\
\text { the employee (e.g. shift } \\
\text { manager, worker) } \\
\text { - image and media support }\end{array}$ & $\begin{array}{l}\text { - Rapid decision making } \\
\text { and transmission } \\
\text { - Localization of a } \\
\text { necessary decision } \\
\text { - Prioritization of decisions }\end{array}$ \\
\hline
\end{tabular}

Fig. 2. Collected and clustered customer needs in the industry workshop.

The research team used the collected customer needs to define the functional requirements for the software development. In an additional internal workshop of the research team the results in Fig. 2 were analyzed in order to define which inputs are constraints $(\mathrm{Cs})$ and which ones are functional requirements. 


\subsection{Definition of high-level functional requirements (FRs) and design parameters (DPs)}

The highest level of FRs and DPs can be expressed as follows:

$\mathrm{FR}_{0} \quad$ Manage the production shopfloor in a smart way.

$\mathrm{DP}_{0} \quad$ Smart Shopfloor Management software.

Based on the outcome of the initial workshop the following high-level Functional Requirements and related Design Parameters were defined:

$\mathrm{FR}_{1}$ Collect real time data of machines, processes, resources and energy

$\mathrm{FR}_{2} \quad$ Avoid inconsistency of data

$\mathrm{FR}_{3} \quad$ Visualize needed and related data everywhere for individual roles in production without using paper

$\mathrm{FR}_{4}$ Monitoring of performance (input-output) in production

$\mathrm{FR}_{5}$ Allow individual and production related data analysis

$\mathrm{FR}_{6}$ Avoid problems and increase reactivity in decision-making if problems arise

$\mathrm{FR}_{7} \quad$ Facilitate acceptance of employees.

$\mathrm{DP}_{1} \quad$ Data Collection module with interfaces and smart sensors

$\mathrm{DP}_{2} \quad$ Data structuring module

$\mathrm{DP}_{3} \quad$ Digital visualization technologies

$\mathrm{DP}_{4}$ Monitoring tools

$\mathrm{DP}_{5} \quad$ Tools for production data analysis

$\mathrm{DP}_{6} \quad$ Problem Prevention and problem solving tools

$\mathrm{DP}_{7} \quad$ Dedicated training of employees and tutorials.

The design matrix on the first level is decoupled and shows the dependencies between the solutions (DPs) and the functional requirements (FRs):

$\left\{\begin{array}{l}F R_{1} \\ F R_{2} \\ F R_{3} \\ F R_{4} \\ F R_{5} \\ F R_{6} \\ F R_{7}\end{array}\right\}=\left[\begin{array}{lllllll}X & O & O & O & O & O & O \\ O & X & O & O & O & O & O \\ O & O & X & O & O & O & O \\ O & O & O & X & O & O & O \\ O & O & O & O & X & O & O \\ O & O & O & X & X & X & O \\ O & O & X & X & X & X & X\end{array}\right]\left\{\begin{array}{l}D P_{1} \\ D P_{2} \\ D P_{3} \\ D P_{4} \\ D P_{5} \\ D P_{6} \\ D P_{7}\end{array}\right\}$

Fig. 3 shows the FR-DP tree of the highest hierarchical levels.

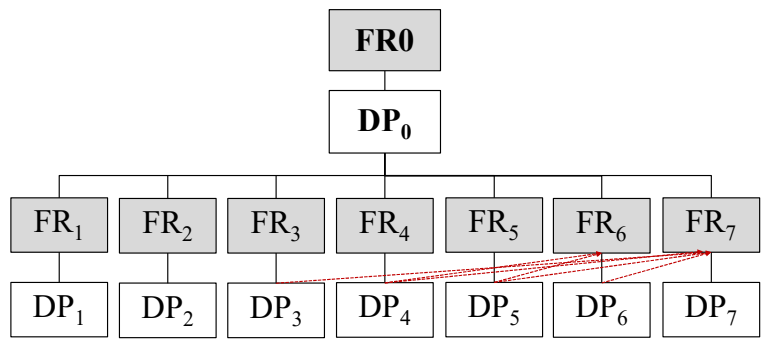

Fig. 3. Highest-level FR-DP tree.

\subsection{Decomposition and mapping process}

The decomposition process of top-level FRs and DPs aims to transform the abstract requirements into more tangible parameters that are close to the daily practice and therefore relevant for implementation. The FR-DP pairs on the highest hierarchical level represented in Fig. 3 are a starting point for the top-down decomposition and mapping process in AD. The decomposition is performed separately for each of the FR-DP pairs shown in Fig. 3 to obtain a better understanding of the process.

\subsubsection{FR $1-D P_{1}-$ Data Collection}

The $\mathrm{DP}_{1}$ Data Collection does not need a further decomposition as this module is already realized in the existing commercial software and works well for the planned software redesign.

\subsection{2 $F R_{2}-D P_{2}-$ Data Structuring}

Same as above occurs also for $\mathrm{DP}_{2}$ Data Structuring. The data structuring method has already been realized and is not part of the redesign.

\subsection{3 $F R_{3}-D P_{3}-$ Digital visualization}

Digital visualization technologies are supporting to visualize specific contents to operators or other users in production. Mobile apps help to visualize data everywhere, while an own function is visualizing only data relevant for the own position (shift-leader, operator, etc.) while an Info Board contains general information. Problems are visualized graphically in the layout as problem map.

$\mathrm{FR}_{3.1}$ Visualize data everywhere.

$\mathrm{FR}_{3.2}$ Visualize relevant data for the own role.

$\mathrm{FR}_{3.3}$ Visualize general information.

$\mathrm{FR}_{3.4}$ Visualize problems transparently.

$\mathrm{DP}_{3.1}$ Mobile App module.

$\mathrm{DP}_{3.2}$ MyRole View module.

$\mathrm{DP}_{3.3}$ Info Board module.

$\mathrm{DP}_{3.4}$ Problem Map module.

The design matrix shows a decoupled design:

$\left\{\begin{array}{l}F R_{3.1} \\ F R_{3.2} \\ F R_{3.3} \\ F R_{3.4}\end{array}\right\}=\left[\begin{array}{llll}X & O & O & O \\ X & X & O & O \\ X & O & X & O \\ X & O & X & X\end{array}\right]\left\{\begin{array}{l}D P_{3.1} \\ D P_{3.2} \\ D P_{3.3} \\ D P_{3.4}\end{array}\right\}$

The Mobile App module consists of an app containing a mobile version of the software. Thus it has a dependency to other FRs. The Info Board module is also able to visualize problems transparently.

\subsubsection{FR4-DP 4 - Monitoring}

Production performance indicators are monitored in a performance monitoring function while energy 
consumption is monitored in an energy cockpit. The smart layout function shows changes in the layout.

$\mathrm{FR}_{4.1}$ Monitoring of production performance.

$\mathrm{FR}_{4.1}$ Monitoring of energy performance.

$\mathrm{FR}_{4.1}$ Monitoring of changes in the layout.

$\mathrm{DP}_{4.1}$ Performance Monitoring.

$\mathrm{DP}_{4.2}$ Energy Cockpit.

$\mathrm{DP}_{4.3}$ Smart Layout.

The design matrix shows an uncoupled design:

$\left\{\begin{array}{l}F R_{4.1} \\ F R_{4.2} \\ F R_{4.3}\end{array}\right\}=\left[\begin{array}{lll}X & O & O \\ O & X & O \\ O & O & X\end{array}\right]\left\{\begin{array}{l}D P_{4.1} \\ D P_{4.2} \\ D P_{4.3}\end{array}\right\}$

\subsubsection{FR5-DP5 - Data Analysis}

The software should not only allow to see general monitoring dashboards but also to do more detailed data analysis using the data stored in the software. Thus the SSFM software provides a digital value stream mapping function in order to compare different situations and to identify potentials for optimization. Further individual data analytics should also be possible.

$\mathrm{FR}_{5.1}$ Allow lean production data analysis.

$\mathrm{FR}_{5.2}$ Enable individual data analysis.

$\mathrm{DP}_{5.1}$ Digital Value Stream Map.

$\mathrm{DP}_{5.2}$ Data Analytics.

The design matrix shows an uncoupled design:

$$
\left\{\begin{array}{l}
\mathrm{FR}_{5.1} \\
\mathrm{FR}_{5.2}
\end{array}\right\}=\left[\begin{array}{ll}
\mathrm{X} & 0 \\
0 & \mathrm{X}
\end{array}\right]\left\{\begin{array}{l}
\mathrm{DP}_{5.1} \\
\mathrm{DP}_{5.2}
\end{array}\right\}
$$

\subsubsection{FR6-DP 6 - Problem Management}

Problems due to machine stops should be avoided in future through early warning systems or predictive maintenance. A digital problem issue tracking function should also reduce the duration of the procedure to solve a problem. The introduction of a location based decision making can further improve also the reactivity for problem solving. This means that e.g. the nearest shift leader will be informed if the production system identifies a problem where a certain decision is needed.

$\mathrm{FR}_{6.1}$ Prevent stops of production machines.

$\mathrm{FR}_{6.2}$ Reduce duration of problem solving.

$\mathrm{FR}_{6.3}$ Increase reactivity in problem solving.
$\mathrm{DP}_{6.1}$ Predictive maintenance module.

$\mathrm{DP}_{6.2}$ Issue tracking.

$\mathrm{DP}_{6.3}$ Location based decision.

The design matrix shows a decoupled design:

$\left\{\begin{array}{l}\mathrm{FR}_{6.1} \\ \mathrm{FR}_{6.2} \\ \mathrm{FR}_{6.3}\end{array}\right\}=\left[\begin{array}{ccc}\mathrm{X} & \mathrm{O} & \mathrm{O} \\ \mathrm{O} & \mathrm{X} & \mathrm{O} \\ \mathrm{X} & \mathrm{X} & \mathrm{X}\end{array}\right]\left\{\begin{array}{l}\mathrm{DP}_{6.1} \\ \mathrm{DP}_{6.2} \\ \mathrm{DP}_{6.3}\end{array}\right\}$

Predictive maintenance as well as issue tracking increases the reactivity for problem solving showed in the matrix by the dependencies of the DPs with the last FR.

\subsection{7 $F R_{7}-D P_{7}-$ Acceptance of users}

It is crucial for the implementation of such a Shopfloor management system that all user are accepting the software. Thus the AD design foresees two further lower level FR-DP pairs.

$\mathrm{FR}_{7.1}$ Support users if problems arise.

$\mathrm{FR}_{7.2}$ Increase skills of users in data management.

$\mathrm{DP}_{7.1}$ Online Tutorial.

$\mathrm{DP}_{7.2}$ Dedicated trainings in the SSFM software.

The design matrix shows a decoupled design:

$\left\{\begin{array}{l}\mathrm{FR}_{7.1} \\ \mathrm{FR}_{7.2}\end{array}\right\}=\left[\begin{array}{ll}\mathrm{X} & 0 \\ \mathrm{X} & \mathrm{X}\end{array}\right]\left\{\begin{array}{l}\mathrm{DP}_{7.1} \\ \mathrm{DP}_{7.2}\end{array}\right\}$

There is a dependency as the regular use of online tutorials is also helping to train people working with the software.

\subsubsection{Design matrix and summary}

The following design matrix illustrated in Fig. 4 summarizes all higher and lower level FR and DP. Acclaro DFSS (Design for Six Sigma software tool by Functional Specs Inc.) was used to elaborate and check the overall design matrix.

The design matrix is decoupled, which means that the design sequence must be followed in the development work in order to minimize complexity and iterations in the software development process. The AD approach provides software developers with an instrument for sequencing the development of the single software modules in an appropriate manner. 


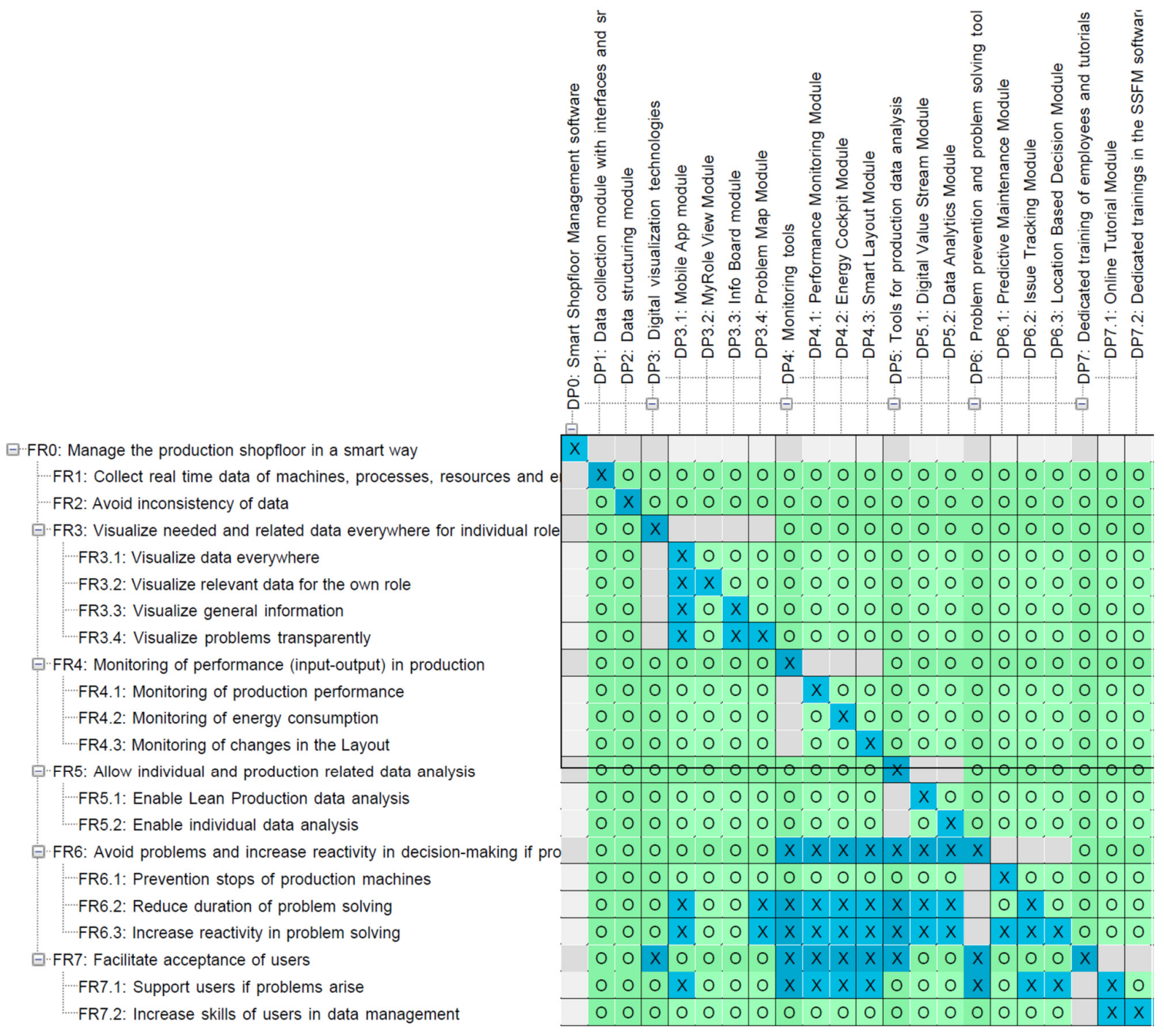

Fig. 4. Summarizing first and second level design matrix.

\section{Architecture and concept of a Smart Shopfloor Management software prototype}

Fig. 5 shows the final concept and structure of modules or functionalities of the software prototype. The module "Data Analytics" enables the user to create individual data analyses in an intuitive way without any specific knowledge, thus using existing data effectively and efficiently. The "Mobile App" module enables the user to access the SSFM system from mobile devices. In order to keep distances short and reaction speed fast, the module "Location-based Decision" supports calling the closest decision authority to the place of the immediate decision. The "myRole View" module enables the user to switch between a standard view and a role-specific view in order to display only that information that is important and useful for their role (e.g. worker, shift-leader). The "Smart Layout" module enables the user to visualize the current situation in production by means of a dynamic graphical layout representation. If the user zooms in or out, more details such as machine status or job data appear. The "Performance Monitoring" module makes it possible to display KPIs or statistics in real time avoiding complex updating of reports. The "Smart Info Board" module enables general information to be displayed to all or specific monitors in production at the touch of a button, eliminating the need for time-consuming manual update of paper. Based on internal data algorithms the "Predictive Maintenance" module determines automatically, when the next maintenance intervals are to be carried out. The "Problem Map" module graphically shows where quality problems arise in the company and therefore enables intuitive and quick detection of problem areas or machines. The "Issue Tracking" module digitally tracks the systematic processing of occurring problems in production by allowing the status of open problems to be continuously and in real time updated by the parties involved. The "Energy Cockpit" module shows the current energy consumption in the company and warns the user as soon as the consumption exceeds a defined warning limit or follows a negative or positive trend. The "Digital Value Stream Map" module is the digital image

\footnotetext{
* Corresponding author: erwin.rauch@unibz.it
} 
of a traditional value stream map, which is updated continuously and in real time and thus avoids timeconsuming manual data collection. The "Dedicated Trainings" module offers access to training documents or video material directly at the workplace in order to facilitate the training phase of new employees at the workplace or during the start-up of new products. The last module "Online Tutorial" enables decentralized access to tutorials for problem solving and for frequently asked questions.

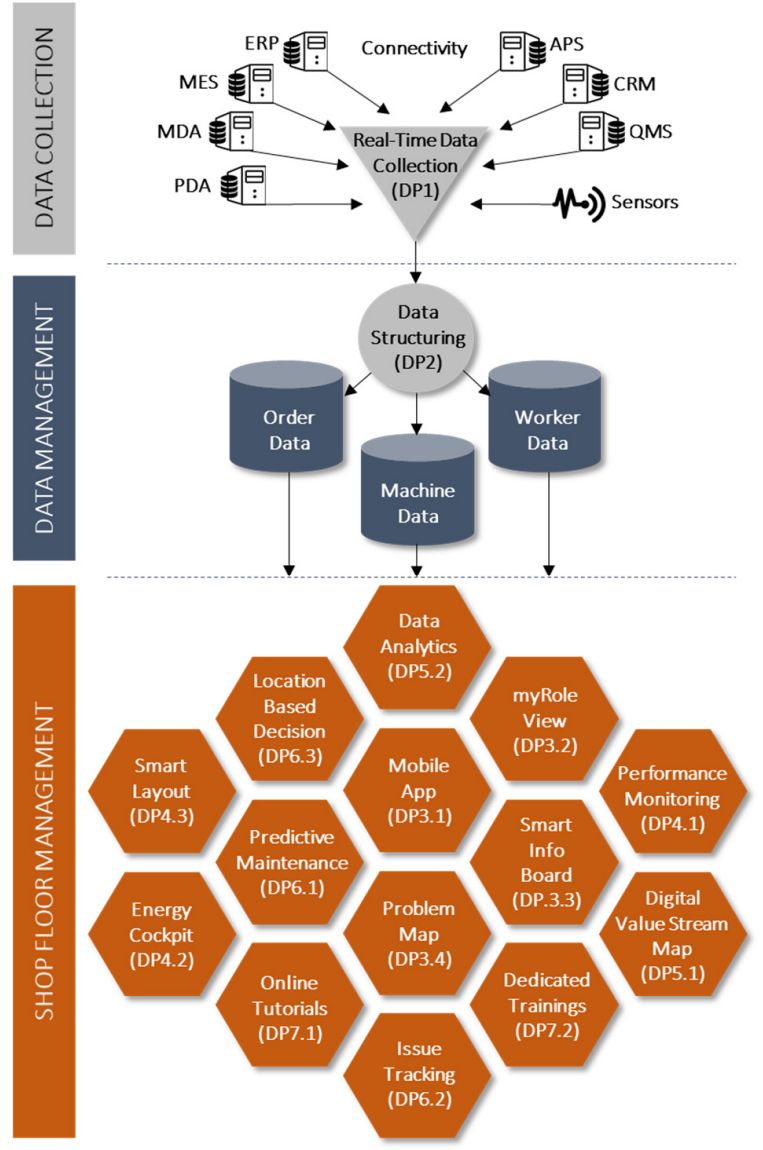

Fig. 5. Future modules of the SSFM software prototype.

\section{Conclusion and outlook for further research}

This work summarizes current results of an ongoing research on SSFM. Previous studies have shown that small and medium-sized companies in particular require simplified and modular solutions for digitization in the shop floor management [16, 17]. Taking this need into account, this work tries to define a basic concept for bringing shopfloor management to a new digital level. Through a higher connectivity of production systems, existing data can be used for a more intelligent SFM. Thus, a framework based on three layers has been developed to design and realize a prototype application of a SSFM in the lab. Aim of this SSFM system is to support indirect and direct people in production and to change from a paper-based SFM system to a digital one. The currently commercialized SSFM application visual shop floor ${ }^{\circledR}$ from the research partner Solunio will be used in a next step to develop, realize and test the newly identified modules shown in the AD decomposition and in Fig. 5. The AD approach supports the developers to define the right sequence for software development as the design matrix shows a decoupled design. An important task in the context of software development will be to make the user aware of which functional requirements have been implemented via the various software modules (DPs), so that the user can make full use of the developed SSFM. The testing of the new software prototype will take place in the Smart Mini Factory Laboratory of the Free University of Bolzano which focuses innovative applications of Industry 4.0. Further tests in an industrial environment should help to evaluate the suitability of this software prototype in industrial companies and especially in small and medium sized companies.

This project has received funding from the Free University of Bolzano under the grant agreement TN2079 (project title: Smart Shopfloor - Development of a software prototype for intelligent Shopfloor Management through Industry 4.0 technologies).

\section{References}

1. U. Sendler. Industrie 4.0 - Beherrschung der industriellen Komplexität mit SysLM (in German: Industry 4.0 - mastering industrial complexity with SysLM). Munich: Springer, 2013.

2. D. Spath, O. Ganschar, S. Gerlach, T. K. Hämmerle and S. Schlund. Manufacturing work of the future Industry 4.0. Stuttgart: Fraunhofer Verlag; 2013.

3. M. Gneuss. Als die Werkstücke laufen lernten. Industrie 4.0: Die vierte industrielle Revolution (in German: When the workpieces learned to walk. Industry 4.0: the fourth industrial revolution). Berlin: Reflex; 2014.

4. C. Hertle, J. Hambach, A. Meißner, S. Rossmann, J. Metternich, J. Rieger. Digital shopfloor management - New ideas for improvements in production. Productivity Management, vol. 22, no. 1, pp.59-61, 2017.

5. L. M. Liao, C. J. Huang and G. H. Lin. A case study of production scheduling and shop floor control for hybrid flexible flowshop. In: Proceedings of the 6th International Conference on Industrial Engineering and Operations Management, Kuala Lumpur, Malaysia, 2016.

6. U. Dombrowski, T. Belz and F. Jäger F. Shopfloor management in the loop control of the implementation of Lean Production Systems (LPS): Supporting lean leadership with corporate-wide and standardized performance measurement systems. Zeitschrift für wirtschaftlichen Fabrikbetrieb, vol. 109, no. 1-2, pp. 20-25, 2014.

7. U. Dombrowski, T. Belz and F. Jäger. The use of shop floor management for support of quality management systems - operational implementation of the requirements of ISO 9001: 2015 in manufacturing 
companies. Zeitschrift für wirtschaftlichen Fabrikbetrieb, vol. 111, no. 4, pp. 169-173, 2016.

8. Bundesministerium für Bildung und Forschung. Zukunftsbild „Industrie 4.0“. Berlin: Bundesministerium für Bildung und Forschung, 2012.

9. E. Rauch, S. Seidenstricker, P. Dallasega and R. Hämmerl. Collaborative Cloud Manufacturing: Design of Business Model Innovations Enabled by Cyberphysical Systems in Distributed Manufacturing Systems. Journal of Engineering, Article ID 1308639, 2016.

10. H. Kagermann, W. Wahlster and J. Helbig. Umsetzungsempfehlungen für das Zukunftsprojekt Industrie 4.0. Abschlussbericht des Arbeitskreises Industrie 4.0, Promotorengruppe Kommunikation der Forschungsunion Wirtschaft - Wissenschaft. Frankfurt: acatech - Deutsche Akademie der Technikwissenschaften e.V., 2013.

11. F. Shrouf and G. Miragliotta. Energy management based on Internet of Things: practices and framework for adoption in production management. Journal of Cleaner Production, vol. 100, pp. 235-246, 2015.

12. A. Sanders and J. Wulfsberg, J. Industrie 4.0: Shopfloor Management im Wandel: Konzeptionelle Handlungsempfehlungen. Zeitschrift für wirtschaftlichen Fabrikbetrieb, vol. 110, no. 10, pp. 653-656, 2015.

13. N. P. Suh. Axiomatic design theory for systems. Research in engineering design, vol. 10, no. 4, pp. 189-209, 1998.

14. N. P. Suh. Axiomatic design: Advances and applications. New York: Oxford University Press, 2001.

15. N. P. Suh and S. H. Do. Axiomatic design of software systems. CIRP Annals-Manufacturing Technology, vol. 49, no. 1, pp. 95-100, 2000.

16. P. R. Spena, P. Holzner, E. Rauch, R. Vidoni and D. T. Matt. Requirements for the Design of flexible and changeable Manufacturing and Assembly Systems: a SME-survey. Procedia CIRP, vol. 41, pp. 207-212, 2016.

17. D. T. Matt and E. Rauch. Design of a scalable modular production system for a two-stage food service franchise system. International Journal of Engineering Business Management, vol. 4, no. 1, pp. 4-32, 2012. 